\title{
A Role for Prostaglandin E in Defective Insulin Secretion and Carbohydrate Intolerance in Diabetes Mellitus
}

\author{
R. Paul Robertson and Mei Chen \\ From the University of Washington School of Medicine and Veterans Administration Hospital, \\ Seattle, Washington 98108
}

A B S T RACT Prostaglandin $\mathrm{E}_{2}\left(\mathrm{PGE}_{2}\right)$ infusion in normal humans inhibited acute insulin responses to a glucose $\left(5 \mathrm{~g}\right.$ i.v.) pulse (response before $\mathrm{PGE}_{2}=593$ $\pm 104 \%$; during $\mathrm{PGE}_{2}=312 \pm 55 \%$; mean $\pm \mathrm{SE}$, mean change $3-5 \mathrm{~min}$ insulin, $\%$ basal, $P<0.005$ ). This effect was associated with a decrease in glucose disappearance rates $\left(\mathrm{K}_{\mathrm{G}}\right.$ before $\mathrm{PGE}_{2}=0.73 \pm 0.07$; during $\left.\mathrm{PGE}_{2}=0.49 \pm 0.06 \% / \mathrm{min}, P<0.025\right)$. Acute insulin responses to arginine $(2 \mathrm{~g}$ i.v.) were not affected by $\mathrm{PGE}_{2}$ (response before $\mathrm{PGE}_{2}=592 \pm 164 \%$; during $\left.\mathrm{PGE}_{2}=590 \pm 118 \% ; P=\mathrm{NS}\right)$. Infusion of sodium salicylate (SS), an inhibitor of endogenous prostaglandin synthesis, augmented acute insulin responses to glucose in normals (response before SS $=313 \pm 62 \%$; during SS $=660 \pm 86 \% ; P<0.001)$. In adult-onset diabetes with fasting hyperglycemia, SS restored absent acute insulin responses to glucose (20 g i.v.) pulses (response before SS $=5 \pm 6 \%$; during SS $=97 \pm 24 \% ; P<0.005)$. This was accompanied by a fourfold augmentation in second phase insulin secretion (second phase before SS $=1,696 \pm 430 \%$; during SS $=5,176 \pm 682 \%$; change 10-60 min insulin, $\frac{\mu \mathrm{U}}{\mathrm{ml}} \cdot \min , \%$ basal, $\left.P<0.001\right)$ and by acceleration of glucose disappearance rates $\left(\mathrm{K}_{\mathbf{G}}\right.$ before $\mathrm{SS}=0.56$ \pm 0.06 ; during $\mathrm{SS}=1.02 \pm 0.17 \% / \mathrm{min}, \quad P<0.005$ ). These findings uniquely demonstrate that $(a) \mathrm{PGE}_{2}$ inhibits glucose-induced acute insulin responses and decreases glucose disposal in nondiabetic humans and (b) SS restores acute insulin responses, augments second phase insulin secretion, and accelerates glucose disposal in hyperglycemic, adultonset diabetics. It is hypothesized that endogenous

This work was presented at meetings of the Western Section of The American Federation for Clinical Research, Carmel, Calif., 3 February 1977 and The Association of American Physicians, Washington, D. C., 2 May 1977.

Received for publication 14 March 1977 and in revised form 13 May 1977.
PGE synthesis may play a role in defective insulin secretion and glucose intolerance in diabetes mellitus.

\section{INTRODUCTION}

Adult-onset diabetic patients with fasting hyperglycemia lack acute insulin responses (first phase insulin secretion) to glucose (1). This abnormality in pancreatic B-cell function appears to be related specifically to glucose since acute insulin responses are present to a variety of other secretogogues, such as isoproterenol, amino acids, secretin, and glucagon (2-5). Elucidation of the underlying mechanism which causes defective acute insulin responses is important not only because this response is consistently absent in adult-onset diabetes mellitus, but also because the acute response is normally a major determinant of intravenous glucose tolerance (6).

Lack of acute responses to glucose stimulation could be due to a defect within the pancreatic $B$ cell or suppression of its normal function by endogenous factors. Consequently, considerable interest has developed in endogenous substances that can inhibit acute insulin responses. The only endogenous substances which have been demonstrated to be inhibitory in normal humans are catecholamines and somatostatin $(7-10)$. We have previously reported that prostaglandins of the $E$ series inhibit glucose-induced secretion in vivo in dogs $(11,12)$. Unlike catecholamines and somatostatin, however, inhibition by prostaglandin $\mathrm{E}$ of insulin secretion is not reversed by $\alpha$-adrenergic blockade $(11,13)$. Since there have been no reported investigations concerning the effects of prostaglandins upon acute insulin responses in humans, this investigation was designed to answer two questions. ( $a$ ) What are the effects of prostaglandin $\mathrm{E}$ upon acute insulin responses and glucose tolerance in normal humans? $(b)$ What are the effects of inhibition of endogenous prostaglandin $E$ synthesis in normal and in diabetic humans upon insulin secretion and glu- 
cose tolerance? To answer these questions, we have examined $(a)$ the effect of intravenous prostaglandin $\mathrm{E}_{2}$ infusions in normal volunteers upon basal levels of insulin and glucose, and their responses to intravenous glucose or arginine stimulation; and $(b)$ the effect of an infusion of an inhibitor of endogenous prostaglandin synthesis, sodium salicylate (14), in normal volunteers and in adult-onset hyperglycemic diabetics upon basal levels of insulin and glucose and their responses to intravenous glucose stimulation.

\section{METHODS}

The normal volunteers had no personal or family history of diabetes mellitus. The diabetic subjects were neither ketotic nor insulin dependent and none had received oral hypoglycemic agents for at least 5 days before the experiments. All studies were conducted after a $12 \mathrm{~h}$ fast and at bed rest between the hours of 8 a.m. and 1 p.m. Intravenous $0.85 \%$ sodium chloride infusions were begun in both arms 30 min before administration of the various test agents. All blood samples were drawn through three-way stopcocks to avoid additional venipunctures during the infusions.

Prostaglandin $\mathrm{E}_{2}\left(\mathrm{PGE}_{2}\right)^{1}(10 \mu \mathrm{g} / \mathrm{min})$ or sodium salicylate (40 $\mathrm{mg} / \mathrm{min}$ ) were infused intravenously. This $\mathrm{PGE}_{2}$ infusion rate was chosen because it is the maximal rate possible that does not produce symptoms or blood pressure changes. Glucose stimulation was provided by injecting intravenously $5 \mathrm{~g}$ of glucose in less than $3 \mathrm{~s}$ or $20 \mathrm{~g}$ of glucose in less than $20 \mathrm{~s}$. The smaller dose of glucose was used to determine whether sodium salicylate could augment the insulin response in normals to this submaximal stimulus. The larger dose of glucose, which causes maximal acute insulin response in normals, was used to determine whether salicylate could restore absent insulin responses in diabetic patients. Arginine stimulation was provided by injecting intravenously the half-maximal dose of $2 \mathrm{~g}$ in less than $5 \mathrm{~s}$. Blood samples were drawn at $-15,-10,-5$, and 0 min before the beginning of each study. Additional samples were drawn at $2,3,4,5,10,15,20,25,30,45,60,90$, and 120 min after the intravenous pulses had been given. The 90 - and 120min samples were omitted after the 5-g glucose pulse. Basal insulin levels were calculated as the mean of the four samples drawn before the first pulse. The acute insulin response (mean $3-5 \mathrm{~min}$ change insulin, \% basal) was calculated as the mean of the 3-, 4-, and 5-min post-glucose injection values for a given subject from which was subtracted the insulin level immediately before the pulse for that subject; this number was then expressed as a percentage of the basal value. Second phase insulin secretion was calculated as the insulin area from 10 to $60 \mathrm{~min}$ after the $20-\mathrm{g}$ pulse which was above the insulin level immediately before the pulse. This area was expressed as a percentage of the basal insulin level. Glucose disappearance rates $\left(K_{G}\right)$ were calculated as the slope of the regression line describing the inverse relationship between sampling times (10 to $30 \mathrm{~min}$ ) and the natural logarithm of plasma glucose concentration and were expressed as percent per minute. After collection in EDTA, blood samples for glucose and insulin were kept at $4^{\circ} \mathrm{C}$ until the end of the study and then centrifuged at $2,500 \mathrm{rpm}$ and $4^{\circ} \mathrm{C}$. The plasma was

${ }^{1}$ Abbreviations used in this paper: $\mathrm{K}_{\mathrm{G}}$, glucose disappearance rate; $\mathrm{PGE}_{2}$, prostaglandin $\mathrm{E}_{2}$. frozen for future analysis for glucose by an AutoAnalyzerferricyanide method (15) and for insulin by a modification of the method of Morgan and Lazarow (16). Additional samples of blood were allowed to clot and the serum was measured for salicylate levels (17). Statistical comparisons were performed by Student's $t$, paired $t$, and Wilcoxon rank-sum tests.

\section{RESULTS}

The effect of $P G E_{2}$ infusions in normal subjects upon basal levels of insulin and glucose and their responses to intravenous glucose or arginine pulses. All normal subjects had fasting plasma glucose levels less than $112 \mathrm{mg} / \mathrm{dl}$. All subjects had acute insulin responses after $5 \mathrm{~g}$ of intravenous glucose (Fig. 1); base-line levels were reestablished by $60 \mathrm{~min}$ after the pulse. During the first $30 \mathrm{~min}$ of a subsequent $\mathrm{PGE}_{2}$ infusion, there was no change in the mean insulin level. After the second glucose pulse, an acute insulin response was observed; however, this response was significantly less than the response to the first glucose pulse (first response $=593 \pm 104 \%$; second response $=312 \pm 55 \%$; mean change 3-5 min insulin, \% basal; mean $\pm \mathrm{SE}, n=10, P<0.005$ ). In control studies which were identical except that saline rather than $\mathrm{PGE}_{2}$ was infused (Fig. 2), there was no difference between the acute insulin responses after the glucose pulses (first response $=518 \pm 115 \%$; second

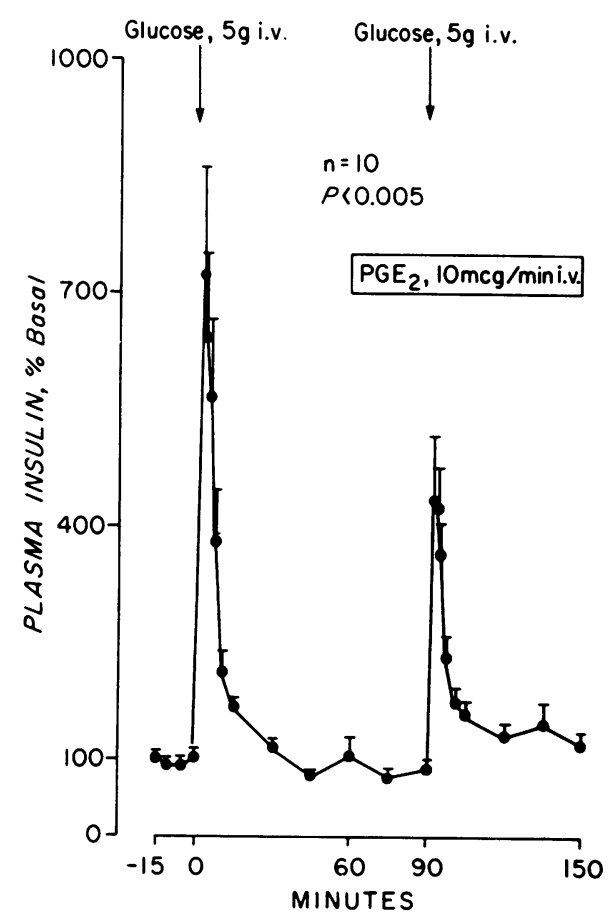

Figure 1 Circulating insulin levels in response to glucose pulses given before and during an infusion of $\mathrm{PGE}_{2}$ in normal humans. 


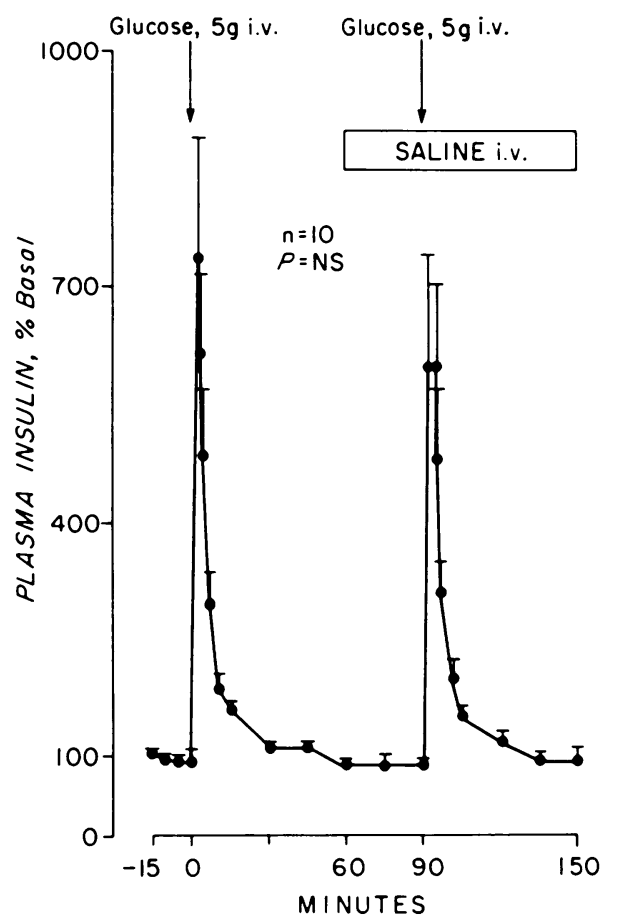

Figure 2 Circulating insulin levels in response to glucose pulses given before and during an infusion of saline in normal humans.

response $=464 \pm 102 \% ; n=10, P=$ NS) nor was there a change in mean insulin level during the first $30 \mathrm{~min}$ of the saline infusion. Glucose disappearance rates were decreased after the second glucose pulse compared to those after the first glucose pulse in the group receiving $\mathrm{PGE}_{2}$ infusion (Table I; first pulse $\mathrm{K}_{\mathrm{G}}$ $=0.73 \pm 0.07$; second pulse $\mathrm{K}_{\mathrm{G}}=0.49 \pm 0.06 \% / \mathrm{min}, P$ $<0.025)$. There was no difference in $\mathrm{K}_{\mathrm{G}}$ after the first and second glucose pulses in the control group

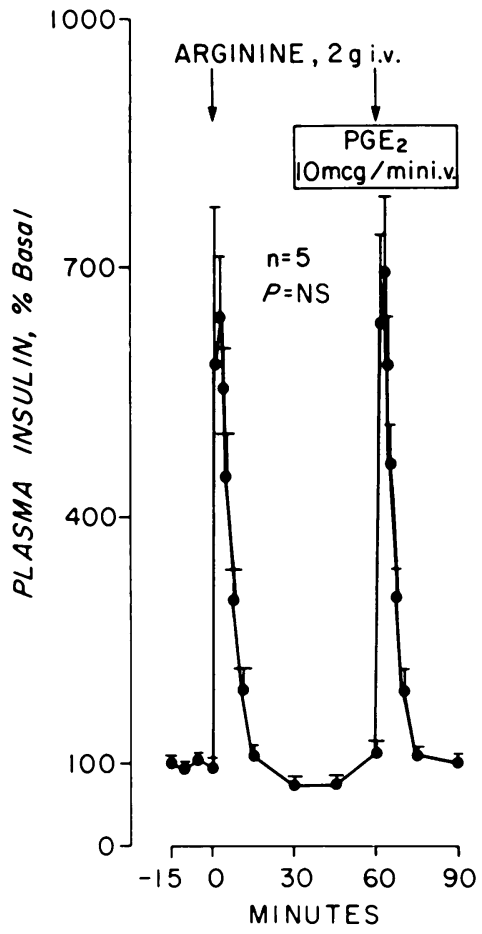

Figure 3 Circulating insulin levels in response to arginine pulses before and during an infusion of $\mathrm{PGE}_{2}$ in normal humans.

(first pulse $\mathrm{K}_{\mathrm{G}}=0.79 \pm 0.10$; second pulse $\mathrm{K}_{\mathrm{G}}=0.80$ $\pm 0.06 \% / \mathrm{min}, P=\mathrm{NS}$ ). There was no difference between the acute insulin responses after intravenous arginine pulses before and during $\mathrm{PGE}_{2}$ infusion (Fig. 3; first response $=592 \pm 164 \%$; second response $=590 \pm 118 \% ; n=5, P=\mathrm{NS}$ ).

The effect of sodium salicylate infusion in normal subjects upon basal levels of insulin and glucose and their responses to intravenous glucose. The acute

TABLE I

Plasma Glucose Levels before (Basal) and at Various Times during the Experiments with PGE Saline Control, and Sodium Salicylate (SS) Infusions Illustrated in Figs. 1, 2, and 4

\begin{tabular}{|c|c|c|c|c|c|c|c|c|}
\hline & & \multicolumn{5}{|c|}{ Plasma glucose } & \multirow[b]{2}{*}{ lst $K_{i}$} & \multirow[b]{2}{*}{ 2nd $K_{G}$} \\
\hline & & Basal & $60 \mathrm{~min}$ & $90 \mathrm{~min}$ & $120 \mathrm{~min}$ & $150 \mathrm{~min}$ & & \\
\hline & & \multicolumn{5}{|c|}{$m g / d l$} & \multicolumn{2}{|c|}{$\% / \min$} \\
\hline \multirow{2}{*}{$\begin{array}{l}\mathrm{PGE}_{2} \text { with glucose } \\
\text { pulses, } n=10\end{array}$} & mean & 96 & 96 & 102 & & & 0.73 & 0.49 \\
\hline & SE & \pm 2 & \pm 2 & \pm 1 & & & 0.07 & 0.06 \\
\hline \multirow{2}{*}{$\begin{array}{l}\text { Saline with glucose } \\
\text { pulses, } n=10\end{array}$} & mean & 100 & 99 & 99 & & & 0.79 & 0.80 \\
\hline & $\mathrm{SE}$ & \pm 3 & \pm 2 & \pm 2 & & & 0.10 & 0.06 \\
\hline \multirow{2}{*}{$\begin{array}{l}\text { SS with glucose } \\
\text { pulses, } n=6\end{array}$} & mean & 92 & 92 & & 90 & 95 & 0.78 & 0.89 \\
\hline & $\mathrm{SE}$ & \pm 3 & \pm 2 & & \pm 3 & \pm 2 & 0.11 & 0.14 \\
\hline
\end{tabular}

Glucose disappearance rates after the first and second glucose pulses are designated 1st $K_{G}$ and 2nd $\mathrm{K}_{\mathrm{G}}$, respectively. 
insulin response to a glucose pulse in the group of normal subjects receiving a sodium salicylate infusion was significantly greater than the response to a glucose pulse before the infusion (Fig. 4; first response $=313 \pm 62 \%$; second response $=660 \pm 86 \% ; n=6$, $P<0.001)$. Compared to preinfusion levels, sodium salicylate itself caused an increase in circulating insulin before the glucose pulse (preinfusion level $=115 \pm 17 ; 60 \mathrm{~min}$ after onset of infusion $=196 \pm 26$ $\%$ basal, $P<0.01$ ). There was a small but statistically insignificant increase in the mean glucose disappearance rate after the second glucose pulse compared to that after the first (Table $\mathrm{I}$; first pulse $\mathrm{K}_{\mathrm{G}}=\mathbf{0 . 7 8}$ \pm 0.11 ; second pulse $\mathrm{K}_{\mathrm{G}}=0.89 \pm 0.14 \% / \mathrm{min}, P=\mathrm{NS}$ ).

The effect of sodium salicylate infusion in adultonset diabetics upon basal levels of insulin and glucose and their responses to intravenous glucose. The mean fasting plasma glucose level of the diabetic subjects receiving sodium salicylate was $196 \pm 19$ $\mathrm{mg} / \mathrm{dl}$ (Table II). There was no mean acute insulin response to $20 \mathrm{~g}$ of intravenous glucose in this group of subjects (Fig. 5; response $=5 \pm 6 \%, n=12, P$ $=\mathrm{NS})$. In contrast, after $60 \mathrm{~min}$ of sodium salicylate infusion, a second glucose pulse elicited acute insulin responses (response $=97 \pm 24 \%, P<0.005$ ). In addition, second phase insulin secretion was augmented (second phase after first pulse $=1,696$

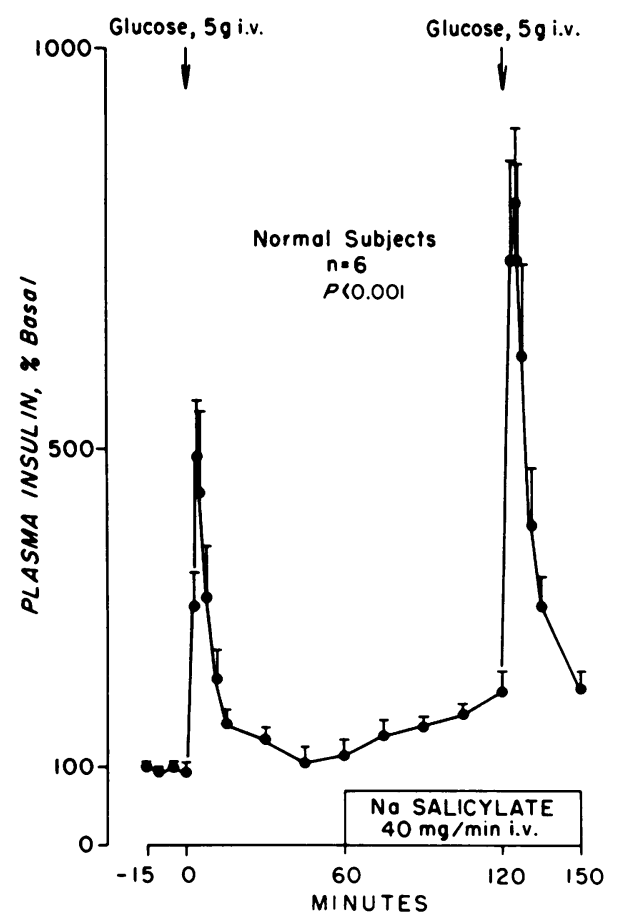

FIGURE 4 Circulating insulin levels in response to glucose pulses before and during an infusion of sodium salicylate in normal humans. $\pm 430 \%$; after second pulse $=5,176 \pm 682 \%$; change 10-60 min insulin, $\frac{\mu \mathrm{U}}{\mathrm{ml}} \cdot \min , \%$ basal; $\left.P<0.001\right)$.

Compared to preinfusion levels, sodium salicylate infusion itself caused an increase in circulating insulin (preinfusion level $=125 \pm 7 ; 60$-min level $=231 \pm 21 \%$ basal, $P<0.001)$. The control patients receiving saline rather than sodium salicylate infusion (Table II) had a mean fasting plasma glucose level of $231 \pm 29 \mathrm{mg} / \mathrm{dl}$ which was not significantly different from the group receiving sodium salicylate. This group also failed to have an acute insulin response after the first glucose pulse (Fig. 5; response $=-13 \pm 7 \%, n=6, P=\mathrm{NS})$. In contrast to the patients receiving sodium salicylate, however, this group did not have acute insulin responses to the second glucose pulse (response $=11 \pm 10 \%, P=\mathrm{NS}$ ). No augmentation of second phase insulin secretion was observed (second phase after first pulse $=1,137$ $\pm 562 \%$; after second pulse $=1,950 \pm 915 \% ; P=\mathrm{NS}$ ) Moreover, there was no increase in circulating insulin during infusion of saline (preinfusion level $=127$ \pm 15 ; 60 -min level $=92 \pm 19 \%$ basal, $P=$ NS). There was a significant increase in the mean glucose disappearance rate in the diabetic group receiving salicylate infusion (first pulse $\mathrm{K}_{\mathrm{G}}=0.56 \pm 0.05$; second pulse $\left.\mathrm{K}_{\mathrm{G}}=1.02 \pm 0.17 \% / \mathrm{min}, P<0.005\right)$. There was no change in $\mathrm{K}_{\mathrm{G}}$ in the group receiving saline rather than salicylate infusion (first pulse $\mathrm{K}_{\mathrm{G}}=0.65 \pm 0.08$; second pulse $\mathrm{K}_{\mathrm{G}}=0.72 \pm 0.09 ; P=\mathrm{NS}$ ). The normal and diabetic groups had similar serum salicylate levels during the salicylate infusion (60-min level: normal $=20 \pm 5$; diabetics $=23 \pm 6 ; 90 \mathrm{~min}$ level: normal $=27$ \pm 3 ; diabetics $=27 \pm 7 \mathrm{mg} / \mathrm{dl}, P=\mathrm{NS}$ ).

\section{DISCUSSION}

These data demonstrate that intravenous $\mathrm{PGE}_{2}$ infusion inhibits the acute insulin response to glucose in normal subjects. This inhibition was accompanied by a decrease in glucose removal rates, suggesting that the reduction in insulin release was biologically significant. Neither inhibition of acute insulin responses nor deterioration of glucose disposal was observed in the control group receiving saline rather than $\mathrm{PGE}_{2}$. Acute insulin responses to arginine stimulation were not inhibited by $\mathrm{PGE}_{2}$ which suggests that inhibition of the responses to glucose may represent specific inhibition of glucose-related secretion by $\mathrm{PGE}_{2}$ rather than nonspecific damping of islet secretory mechanisms.

Infusion of sodium salicylate to inhibit endogenous prostaglandin synthesis augmented glucose-induced acute insulin responses in normal subjects. More strikingly, salicylate restored acute insulin responses in 10 of 12 diabetics who had no response before salicylate 
TABLE II

Plasma Glucose Levels before (Basal) and at Various Times during the Experiments with Sodium Salicylate (SS) and Saline Control Infusions Illustrated in Fig. 5

\begin{tabular}{|c|c|c|c|c|c|c|c|c|c|c|c|}
\hline & \multicolumn{4}{|c|}{ Plasma glucose } & \multirow{2}{*}{$\begin{array}{c}\text { Basal } \\
\text { insulin }\end{array}$} & \multicolumn{3}{|c|}{ Pulse 1} & \multicolumn{3}{|c|}{ Pulse 2} \\
\hline & Basal & $120 \mathrm{~min}$ & $180 \mathrm{~min}$ & $240 \mathrm{~min}$ & & $\mathrm{~K}_{\mathrm{G}}$ & AIR & Phase II & $\mathrm{K}_{\mathrm{G}}$ & AIR & Phase II \\
\hline & \multicolumn{4}{|c|}{$m g / d l$} & & $\% / \min$ & \multicolumn{2}{|c|}{ Tc basal } & $\% \min$ & \multicolumn{2}{|c|}{ \% basal } \\
\hline SS & & & & & & & & & & & \\
\hline 1 & 122 & 128 & 78 & 94 & 16 & 0.90 & 31 & 2,805 & 1.53 & 150 & 9,485 \\
\hline 2 & 126 & 132 & 110 & 122 & 20 & 0.69 & 15 & 4,550 & 1.20 & 255 & 12,188 \\
\hline 3 & 129 & 146 & 110 & 127 & 25 & 0.39 & -28 & 1,880 & 1.40 & 92 & 6,260 \\
\hline 4 & 143 & 151 & 108 & 113 & 7 & 0.55 & 14 & 2,008 & 0.83 & 57 & 7,795 \\
\hline 5 & 146 & 149 & 96 & 50 & 8 & 0.71 & 0 & 2,608 & 2.49 & 200 & 10,695 \\
\hline 6 & 195 & - & 170 & 190 & 25 & 0.57 & -4 & 1,510 & 0.85 & 52 & 4,480 \\
\hline 7 & 206 & 241 & 212 & 242 & 11 & 0.48 & -18 & 405 & 0.82 & 164 & 8,155 \\
\hline 8 & 208 & 228 & 209 & 238 & 8 & 0.35 & 13 & 1,955 & 0.19 & 75 & 3,958 \\
\hline 9 & 232 & 236 & 204 & 213 & 31 & 0.73 & 13 & 558 & 0.75 & 81 & 2,962 \\
\hline 10 & 265 & 287 & 266 & 300 & 5 & 0.53 & 20 & 2,900 & 0.44 & -20 & 9,800 \\
\hline 11 & 276 & 295 & 250 & 289 & 47 & 0.19 & -23 & -965 & 0.81 & 60 & 4,705 \\
\hline 12 & 303 & 316 & 276 & 320 & 8 & 0.58 & 25 & 138 & 0.89 & 0 & 1,985 \\
\hline Mean & 196 & 210 & 174 & 192 & 18 & 0.56 & 5 & 1,696 & 1.02 & 97 & 6,872 \\
\hline SE & 19 & 21 & 21 & 26 & 4 & 0.05 & 6 & 430 & 0.17 & 24 & 950 \\
\hline \multicolumn{12}{|l|}{ Saline } \\
\hline 1 & 148 & 153 & 122 & 165 & 26 & 0.46 & -12 & 2,048 & 0.86 & 12 & 1,678 \\
\hline 2 & 151 & 154 & 118 & 171 & 6 & 1.00 & -17 & 2,210 & 0.98 & 50 & 6,268 \\
\hline 3 & 209 & 211 & 179 & 219 & 12 & 0.46 & 0 & 2,665 & 0.88 & -17 & 1,373 \\
\hline 4 & 276 & 286 & 264 & 310 & 7 & 0.74 & 14 & 665 & 0.66 & 0 & 338 \\
\hline 5 & 292 & 304 & 280 & 312 & 21 & 0.68 & -33 & -788 & 0.52 & -5 & 78 \\
\hline 6 & 311 & 304 & 286 & 316 & 16 & 0.54 & -31 & 23 & 0.40 & 27 & 1,965 \\
\hline Mean & 231 & 235 & 208 & 249 & 15 & 0.65 & -13 & 1,137 & 0.72 & 11 & 1,950 \\
\hline $\mathrm{SE}$ & 29 & 29 & 32 & 29 & 3 & 0.08 & 7 & 562 & 0.09 & 10 & 915 \\
\hline
\end{tabular}

Glucose disappearance rates $\left(\mathrm{K}_{\mathrm{G}}\right)$, acute insulin responses (AIR), and 2nd phase insulin secretion (Phase II) after the first and second pulses $(20 \mathrm{~g}$ i.v. $)$ are compared.

infusion. In 12 of 12 diabetics, there was on the average a fourfold increase in second phase insulin secretion. The salicylate infusion itself caused a significant rise in circulating insulin before the glucose pulse. Glucose levels at this time in both normal and diabetic patients were not rising. None of these effects were observed in the control studies when saline rather than salicylate was infused in the normal and diabetic groups.

Glucose disappearance rates decreased during $\mathrm{PGE}_{2}$ infusion in normals. There was significant acceleration of these rates in diabetics receiving salicylate infusion. Four of the diabetics reached rates which were within the normal range $(>1.0 \% / \mathrm{min})$. No changes in rates were observed in the normal and diabetic control groups receiving saline rather than salicylate infusions. The fact that the mean increase in rate was not statistically significant in the normal group receiving salicylate may indicate that a maximal rate for a 5-g glucose pulse had already been reached.

The inhibition of acute insulin responses and de-

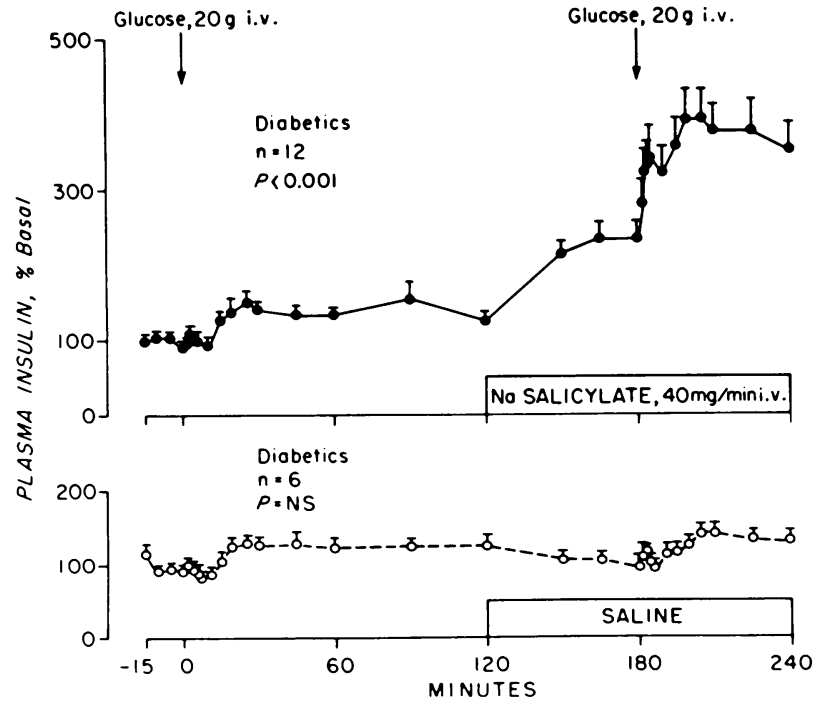

FIGURE 5 Comparison of insulin responses to glucose pulses given before and during sodium salicylate or saline in diabetic humans. 
terioration of glucose disposal caused by $\mathrm{PGE}_{2}$ infusion is in agreement with previous in vivo nonhuman investigation (11-13). The fact that $\mathrm{PGE}_{2}$ infusion did not lower basal insulin levels may be a doserelated phenomenon. Decreases in basal insulin levels were observed in our previously reported experiments in dogs given a $\mathrm{PGE}_{2}$ infusion rate of $10 \mu \mathrm{g} / \mathrm{min}$ $(11,12)$. However, this infusion rate on a body weight basis represents a fourfold greater rate in dogs than in humans. Such dose dependency could explain why the only other published data dealing with the effect of prostaglandins upon circulating insulin and glucose in humans reported negative results (18). These investigators used lower doses of $\mathrm{PGE}_{2}$ than herein reported, studied pregnant females during labor, and did not investigate insulin responses to intravenous glucose.

In general, previous reports (19-24) dealing with the effect of salicylate upon insulin secretion and carbohydrate tolerance have indicated that salicylates tend to elevate circulating insulin and decrease circulating glucose in humans. The earliest published report of a lowering effect of sodium salicylate on glucose in diabetics appears to have been by Ebstein (19) in 1876. Subsequently, Field et al. (23) reported in 1967 that sodium salicylate infusion in healthy controls and patients with mild diabetes mellitus (mean fasting blood glucose level of $83 \mathrm{mg} / \mathrm{dl}$ ) caused an increase in circulating insulin. Although acute insulin responses were not investigated specifically, these authors did find that insulin levels 5 min after intravenous glucose infusion were significantly augmented by salicylate infusion. Since we have now demonstrated that $\mathrm{PGE}_{2}$ infusions in man have the opposite effects of salicylate infusion, it seems likely that the mechanism of salicylate action upon insulin secretion and carbohydrate tolerance may be through inhibition of endogenous prostaglandin synthesis. The recent demonstration by Hamberg (14) in 1972 that sodium salicylate is an effective inhibitor of endogenous $\mathrm{PGE}_{2}$ synthesis in humans supports this hypothesis. However, since salicylates are known to have a variety of effects in humans, its effects on insulin and glucose cannot be specifically ascribed to inhibition of prostaglandin synthesis.

The only other drug which has been reported to restore acute insulin responses to glucose in adultonset diabetics is phentolamine, an $\alpha$-adrenergic antagonist (25). Compared to our findings with phentolamine the beneficial effect of sodium salicylate upon acute insulin responses in diabetics appears to be greater. Moreover, the effect of phentolamine upon second phase insulin secretion was slight whereas there was a four-fold augmentation of second phase secretion by salicylate. It is not known whether $\alpha$ adrenergic events and endogenous prostaglandins are related in a functional sense, although it has been demonstrated that inhibition of insulin secretion by PGE remains intact during $\alpha$-adrenergic blockade (11, 13). In a more general sense, restoration of acute insulin responses to glucose by agents such as phentolamine or salicylates indicates that the loss of this response in adult-onset diabetes can not be due to absolute endogenous insulin deficiency. Our previous demonstration that acute insulin responses to $\beta$ adrenergic stimulation were intact in diabetics who did not respond to intravenous glucose led us to advance the concept of defective glucose recognition by pancreatic B-cells in diabetes (2). If glucose recognition is a major defect, the finding that this defect can be at least partially reversed by drugs such as phentolamine or salicylate may have therapeutic implications. More fundamentally, a more complete understanding of $\alpha$-adrenergic blockade and salicylate action may provide fresh insights into the pathophysiology of abnormal insulin secretion and glucose intolerance in diabetes mellitus.

\section{ACKNOWLEDGMENTS}

We wish to thank Mr. Howard Beiter and Ms. Barbara O'Neill for their skillful technical assistance.

This work was supported by the U. S. Veterans Administration Research and Education Program.

\section{REFERENCES}

1. Brunzell, J. D., R. P. Robertson, R. L. Lerner, W. R. Hazzard, J. W. Ensinck, E. L. Bierman, and D. Porte, Jr. 1976. Relationships between fasting plasma glucose levels and insulin secretion during intravenous glucose tolerance tests. J. Clin. Endocrinol. Metab. 42: 222-229.

2. Robertson, R. P., and D. Porte, Jr. 1973. The glucose receptor: a defective mechanism in diabetes mellitus distinct from the beta adrenergic receptor. J. Clin. Invest. 52: $870-876$.

3. Palmer, J. P., J. W. Benson, R. M. Walter, and J. W. Ensinck. 1976. Arginine-stimulated acute phase of insulin and glucagon secretion in diabetic subjects. J. Clin. Invest. 58: 565-570.

4. Lerner, R. L., and D. Porte, Jr. 1971. Secretin and glucose: stimulation of rapid insulin response from separate functional pools. Clin. Res. 19: 478.

5. Crockford, P. M., W. R. Hazzard, and R. H. Williams. 1969. Insulin response to glucagon. The opposing effects of diabetes and obesity. Diabetes. 18: 216-224.

6. Lerner, R. L., and D. Porte, Jr. 1971. Relationships between intravenous glucose loads, insulin responses and glucose disappearance rate. J. Clin. Endocrinol. Metab. 33: 409-417.

7. Porte, D., Jr. 1967. A receptor mechanism for the inhibition of insulin release by epinephrine in man. J. Clin. Invest. 46: 86-94.

8. Robertson, R. P., and D. Porte, Jr. 1973. Adrenergic modulation of basal insulin secretion in man. Diabetes. 22: $1-8$.

9. Alberti, K. G. M. M., N. J. Christensen, S. E. Christensen, A. P. Hansen, J. Iversen, K. Lundbaek, K. SeyerHansen, and H. Orskov. 1973. Inhibition of insulin secretion by somatostatin. Lancet. II: 1299-1301. 
10. Mortimer, C. H., W. M. G. Tunbridge, D. Carr, L. Yeomans, T. Lind, D. H. Coy, S. R. Bloom, A. Kastin, C. N. Mallison, G. M. Besser, A. V. Schally, and R. Hall. 1974. Effects of growth-hormone release-inhibiting hormone on circulating glucagon, insulin, and growth hormone in normal, diabetic, acromegalic, and hypopituitary patients. Lancet. I: 697-701.

11. Robertson, R. P., D. J. Gavareski, D. Porte, Jr., and E. L. Bierman. 1974. Inhibition of in vivo insulin secretion by prostaglandin $\mathrm{E}_{1} . J$. Clin. Invest. 54: 310-315.

12. Robertson, R. P. 1974. In vivo insulin secretion: prostaglandin and adrenergic interrelationships. Prostaglandins. 6: 501-508.

13. Sacca, L., G. Perez, F. Rengo, I. Pascucci, and M. Condorelli. 1975. Reduction of circulating insulin levels during the infusion of different prostaglandins in the rat. Acta Endocrinol. 79: 266-274.

14. Hamberg, M. 1972. Inhibition of prostaglandin synthesis in man. Biochem. Biophys. Res. Commun. 49: 720-726.

15. Technicon AutoAnalyzer Methodology. Method File, Review. February 11, 1960. Technicon Instruments Corp., Tarrytown, N. Y.

16. Morgan C. R., and A. Lazarow. 1963. Immunoassay of insulin: two antibody system. Plasma insulin levels of normal, subdiabetic and diabetic rats. Diabetes. 12: 115- 126.

17. Salicylate Test Set, Stanbio Laboratory, Inc., San Antonio, Tex. 1974. Stanbio bulletin 290-291.
18. Spellacy, W. N., W. C. Buhi, and K. K. Holsinger. 1971. The effect of prostaglandin $\mathrm{F}_{2} \alpha$ and $\mathrm{E}_{2}$ on blood glucose and plasma insulin levels during pregnancy. Am. J. Obstet. Gynecol. 111: 239-243.

19. Ebstein, W. 1876. Zur therapie des diabetes mellitus, insbesondere uber die anewendeng des salicylsauren natron bei demselben. Klin. Wochschr. 13: 337-340.

20. Williamson, R. T. 1901. On the treatment of glycosuria and diabetes mellitus with sodium salicylate. Br. Med.J. 1: 760-762.

21. Reid, J., and A. I. MacDougall. 1957. Aspirin and diabetes mellitus. Br. Med. J. 2: 1071-1074.

22. Hecht, A., and M. G. Goldner. 1959. Reappraisal of the hypoglycemic action of acetylsalicylate. Metab. Clin. Exp. 8: 418-428.

23. Field, J. B., C. Boyle, and A. Remer. 1967. Effect of salicylate infusion on plasma-insulin and glucose tolerance in healthy persons and mild diabetics. Lancet. I: 11911194.

24. Hyams, D. E., A. N. Howard, I. E. Evans, and S. H. H. Davison. 1970. The effect of 3-methyl salicylic (0cresotinic) acid on plasma insulin and glucose tolerance in diabetic and non-diabetic subjects. Diabetologia. 7: 94-101.

25. Robertson, R. P., J. B. Halter, and D. Porte, Jr. 1976. A role for alpha-adrenergic receptors in abnormal insulin secretion in diabetes mellitus. J. Clin. Invest. 57: 791795 . 